\title{
Implementasi Algoritma Fisher Yates Shuffle pada Aplikasi Belajar Huruf Hijaiyah
}

\author{
Irfan Kurniawan ${ }^{1}$, Siti Sauda² \\ 1.2Informatics Departement, Bina Darma University, Palembang, Indonesia \\ Email: 1irfankurni@outlook.co.id, 2siti_sauda@binadarma.ac.id
}

\begin{abstract}
The form of coaching for early childhood is providing stimulation so that children have readiness to enter the next level of education. One of the basic educations provided by parents is religious education in the form of introduction to hijaiyah letters. Children interacting with smartphones more often than books, causing parents to have basic education such as reading and writing using books to be less attractive to children. From this problem, the writer wants to build a learming media application using smartphone media. This Hijaiyah Letter Learning application was created using the fisher yates shuffle algorithm, by randomizing the questions in this application. Based on the test results that the implementation of the Fisher Yates Shuffle algorithm for randomization of questions in the hijaiyah learning application is running well, there are no questions that appear repeatedly.
\end{abstract}

Keywords: Hijaiyah Letters, Android, Fisher Yates Shuffle, Smartphone, Leaming.

\section{PENDAHULUAN}

Pendidikan usia dini merupakan awal yang penting dan mendasar dalam membantu kesiapan anak untuk menghadapi jenjang pendidikan selanjutnya. Pentingnya pendidikan anak usia dini menuntut pendekatan yang akan digunakan dalam kegiatan belajar yang memfokuskan perhatian anak. Karena anak merupakan generasi penerus dan dambaan bagi setiap orang tua, namun tidak semua orang tua dan pendidik memahami cara yang tepat dalam mendidik anak usia dini. Dalam bidang pendidikan saat ini, penggunaan alat bantu atau media pembelajaran adalah salah satu cara dalam memberikan pendidikan awal bagi anak agar menjadi lebih interaktif.

Belajar membaca $A$ / - Quran merupakan hal yang wajib bagi umat Islam, terutama bagi anak usia dini. Pembelajaran $A /$ - Qurán sangat penting bertujuan untuk menanamkan nilai - nilai pendidikan Islam pada diri anak. Pada saat ini pembelajaran $A$ / - Qur'an banyak dilakukan oleh lembaga sekolah maupun lembaga di luar sekolah. Namun sebelum dapat membaca $A /$ - Quran, anak harus belajar mengenal huruf - huruf hijaiyah terlebih dahulu. 
Huruf merupakan informasi terkecil dari suatu kalimat yang perlu didefinisikan dengan lebih baik agar informasi yang ada dalam kalimat dapat lebih dipahami. Huruf memiliki bentuk yang unik antara satu dengan yang lain, untuk membedakannya disesuaikan dengan karakteristik masing - masing huruf tersebut. Sementara itu huruf hijaiyah merupakan huruf yang digunakan dalam Bahasa Arab, huruf hijaiyah memiliki bentuk bentuk khusus seperti setiap huruf mempunyai beberapa bentuk yang hampir sama tergantung posisi huruf pada suatu kata [1].

Tujuan dari penelitian ini yaitu Mengimplementasikan Algoritma Fisher Yates Shuffle sebagai pengacak pertanyaan dan merancang aplikasi pembelajaran untuk mengenalkan huruf hijaiyah beserta cara pengucapannya. Pada penelitian ini diharapkan dapat memberikan manfaat yaitu sebagai sarana bermain sekaligus media belajar yang interaktif dan memberikan kontribusi pembelajaran tentang pengenalan huruf hijaiyah dan bagi penulis, penelitian ini berguna untuk menambah wawasan mengenai Algoritma Fisher Yates Shuffle. Batasan masalah pada penelitian ini adalah Aplikasi bertipe 2 dimensi, Huruf Hijaiyah yang digunakan berjumlah 28 huruf, Algoritma Fisher Yates Shuffle digunakan sebagai pengacak pertanyaan pada kuis dan Aplikasi yang dibangun berbasis mobile Android.

Android adalah sebuah sistem operasi untuk perangkat mobile berbasis linux yang mencakup sistem operasi, middleware dan aplikasi. Android menyediakan platform terbuka bagi para pengembang untuk menciptakan aplikasi mereka [2]. Aplikasi ini didukung algoritma Fisher Yates Shuffle, Algoritma Fisher Yates Shuffle merupakan salah satu metode pengacakan yang baik digunakan dalam pengembangan suatu aplikasi. Kelebihan algoritma Fisher Yates Shuffle adalah efektivitas dari metode pengacakannya serta kompleksitas algoritmanya yang optimal, sehingga pertanyaan yang disediakan tampil dengan urutan yang acak [3].

\section{METODOLOGI PENELITIAN}

\subsection{Metode Pengembangan Sistem}

Rational Unified Process (RUP) merupakan suatu metode rekayasa perangkat lunak yang dikembangkan dengan mengumpulkan berbagai best practices yang terdapat dalam industri pengembangan perangkat lunak. Ciri utama metode ini adalah menggunakan use - case driven dan pendekatan iteratif untuk siklus pengembangan perangkat lunak. RUP menggunakan konsep object oriented, dengan aktivitas yang berfokus pada pengembangan model dengan menggunakan Unified Model Language (UML)[4]. RUP menyediakan pendefinisian struktur yang lebih baik untuk alur hidup proyek perangkat lunak. 


\section{Journal of Information Technology Ampera}

Vol. 2, No. 3, December 2021 e-ISSN: 2774-2121

https://journal-computing.org/index.php/journal-ita/index

Terdapat empat fase dalam metode ini, yaitu: fase Inception, fase Elaboration, fase Construction, dan fase Transition.

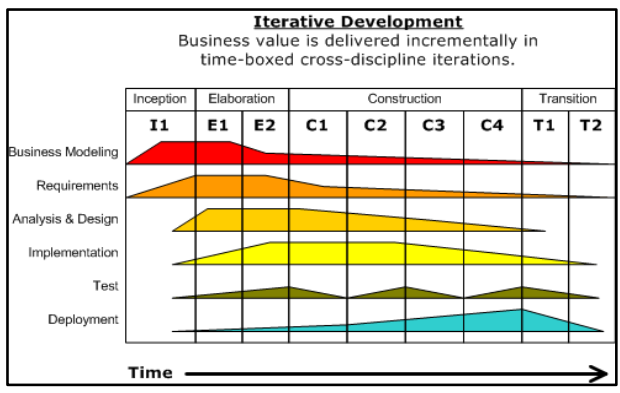

Gambar 1. Fase Rational Unified Process.

\subsection{Analisisi dan Perancangan}

\subsubsection{Fase Inception}

Pada fase ini di mana memodelkan proses bisnis yang dibutuhkan (business modelling), Pemodelan proses bisnis (business modelling) digunakan untuk meninjau, meningkatkan dan membuat sebuah bisnis. Business modelling biasa digambarkan dengan bantuan diagram UML, diagram UML yang digunakan untuk pemodelan bisnis yaitu use case diagram. Use Case Diagram menggambarkan kumpulan use case, aktor dan hubungan mereka. Use case adalah hubungan antara fungsionalitas sistem dengan aktor internal/eksternal dari sistem [5].

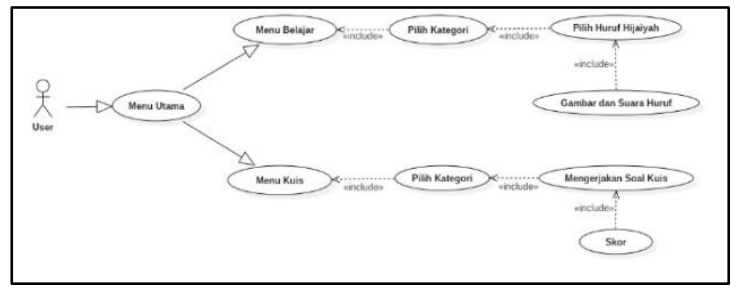

Gambar 2. Use Case Diagram.

\subsubsection{Fase Elaboration}

\section{Analisis Algoritma Fisher Yates Shuffle}

Fisher Yates Shuffle (dinamai berdasarkan penemunya, Ronald Fisher dan Frank Yates) digunakan untuk mengubah urutan yang diberikan secara acak. Permutasi yang dihasilkan oleh algoritma ini muncul dengan probabilitas yang sama [3]. Dalam aplikasi belajar hijaiyah dimisalkan terdapat 8 pertanyaan yang 
akan diacak. Maka didapatkan panjang array $(\mathrm{N})=8$. Langkah - langkah pengacakan dengan Fisher Yates Shuffle sebagai berikut:

1. Ambil satu elemen secara acak ( $k$ ). Nilai $k$ yang boleh diambil adalah elemen yang belum pernah diambil.

2. Tukarkan nilai $(k)$ yang diambil dengan elemen terakhir $(n)$ yang belum diambil.

3. Ulangi selama masih ada elemen yang belum terambil.

Tabel iterasi dari proses manual pengacakan menggunakan algoritma Fisher Yates Shuffle dengan jumlah array $\mathrm{N}=8$ di deskripsikan sebagaimana tabel 1 berikut ini :

Tabel 1. Iterasi Algoritma Fisher Yates Shuffle

\begin{tabular}{|c|c|c|c|}
\hline $\begin{array}{l}\text { Elemen yang diambil } \\
\qquad(\mathrm{k})\end{array}$ & $\begin{array}{c}\text { Elemen } \\
\text { terakhir }(\mathrm{N})\end{array}$ & $\begin{array}{c}\text { Array yang akan di } \\
\text { shuffle }\end{array}$ & $\begin{array}{l}\text { Array yang telah di } \\
\text { shuffle }\end{array}$ \\
\hline 5 & 7 & $0,1,2,3,4,5,6,7$ & $0,1,2,3,4,7,6,5$ \\
\hline 6 & 5 & $0,1,2,3,4,7,6,5$ & $0,1,2,3,4,7,5,6$ \\
\hline 3 & 6 & $0,1,2,3,4,7,5,6$ & $0,1,2,6,4,7,5,3$ \\
\hline 0 & 3 & $0,1,2,6,4,7,5,3$ & $3,1,2,6,4,7,5,0$ \\
\hline 1 & 0 & $3,1,2,6,4,7,5,0$ & $3,0,2,6,4,7,5,1$ \\
\hline 4 & 1 & $3,0,2,6,4,7,5,1$ & $3,0,2,6,1,7,5,4$ \\
\hline 7 & 4 & $3,0,2,6,1,7,5,4$ & $3,0,2,6,1,4,5,7$ \\
\hline 2 & 7 & $3,0,2,6,1,4,5,7$ & $3,0,7,6,1,4,5,2$ \\
\hline \multicolumn{3}{|c|}{ Hasil Pengacakan } & $3,0,7,6,1,4,5,2$ \\
\hline
\end{tabular}

\section{Desain}

Class Diagram menggambarkan struktur statis class di dalam sistem. Class merepresentasikan sesuatu yang ditangani oleh sistem. Class Diagram terdiri dari class, interface, association dan collaboration [4].

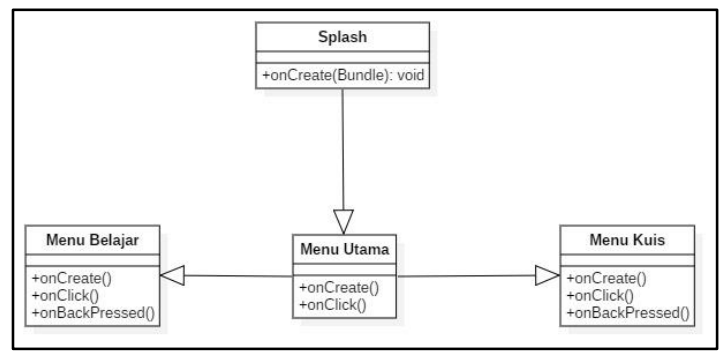

Gambar 2. Class Diagram.

Sequence Diagram menggambarkan interaksi yang menjelaskan bagaimana pesan mengalir dari objek ke objek lainnya [4]. 


\section{Journal of Information Technology Ampera}

Vol. 2, No. 3, December 2021 e-ISSN: 2774-2121

https://journal-computing.org/index.php/journal-ita/index

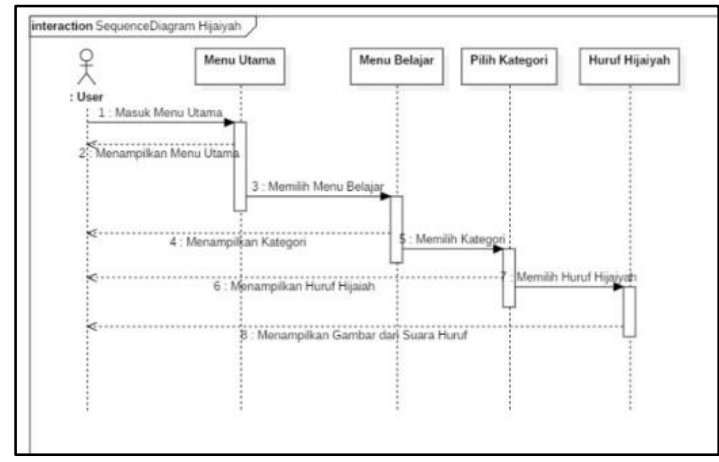

Gambar 3. Sequence Diagram Menu Belajar.

User masuk ke halaman utama, lalu membuka menu belajar, kemudian tampil kategori yang terdiri dari hijaiyah, fathah, kasroh, dhomah, fathah tain, kasroh tain, dan dhomah tain. User memilih hijaiyah, daftar huruf hijaiyah akan tampil disertai dengan suara apabila salah satu huruf di tekan.

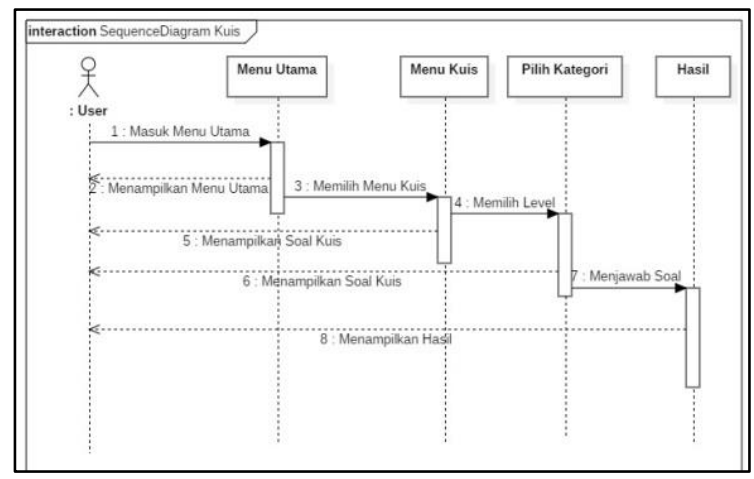

Gambar 4. Sequence Diagram Menu Kuis.

User membuka menu utama, lalu membuka menu kuis, tampil pilihan kategori kuis. User memilih salah satu kategori, akan tampil pertanyaan beserta pilihan jawaban, ketika selesai menjawab semua pertanyaan akan tampil hasil.

\section{HASIL DAN PEMBAHASAN}

\subsection{Uji Coba Algoritma Fisher Yates Shuffle}

Uji coba algoritma Fisher Yates Shuffle dilakukan untuk melihat hasil dari implementasi algoritma tersebut ke dalam aplikasi yang telah dibuat. Algoritma ini akan dicoba beberapa kali untuk mengacak soal 5 dari 28 soal yang ada. 
Journal of Information Technology Ampera

Vol. 2, No. 3, December 2021 e-ISSN: 2774-2121

https://journal-computing.org/index.php/journal-ita/index

Tabel 2. Uji Coba Fisher Yates Shuffle

\begin{tabular}{cc}
\hline PK & Hasil Urutan Baru \\
\hline 1 & $5,3,10,7,12$ \\
\hline 2 & $22,26,23,15,18$ \\
\hline 3 & $23,9,8,12,21$ \\
\hline 4 & $21,28,1,22,2$ \\
\hline 5 & $9,21,17,12,20$ \\
\hline 6 & $8,14,25,2,26$ \\
\hline 7 & $2,26,27,4,28$ \\
\hline 8 & $12,2,8,3,24$ \\
\hline 9 & $7,12,11,14,22$ \\
\hline 10 & $15,3,24,27,11$ \\
\hline 11 & $9,10,27,11,25$ \\
\hline 12 & $17,14,19,23,22$ \\
\hline 13 & $23,4,2,22,6$ \\
\hline 14 & $2,10,22,26,27$ \\
\hline 15 & $8,6,20,13,1$ \\
\hline 16 & $25,1,15,6,19$ \\
\hline 17 & $21,16,8,23,22$ \\
\hline 18 & $26,12,19,2,15$ \\
\hline 19 & $11,27,6,23,17$ \\
\hline 20 & $22,14,15,16,17$ \\
\hline
\end{tabular}

Tabel 2 merupakan hasil uji coba urutan soal baru yang dihasilkan oleh algoritma Fisher Yates Shuffle. Uji coba ini dilakukan pada menu kuis kategori hijaiyah dan fathah. Kolom pertama berjudul PK atau percobaan ke- $\mathrm{x}$, pada kolom kedua hasil urutan baru setelah aplikasi di jalankan.

Tabel 3. Uji Coba Fisher Yates Shuffle

\begin{tabular}{cc}
\hline PK & Hasil Urutan Baru \\
\hline 1 & $28,21,10,3,18$ \\
\hline 2 & $4,13,27,9,17$ \\
\hline 3 & $10,20,27,23,18$ \\
\hline 4 & $24,17,1,9,6$ \\
\hline 5 & $17,11,20,27,8$ \\
\hline 6 & $18,3,6,7,23$ \\
\hline
\end{tabular}


Journal of Information Technology Ampera

Vol. 2, No. 3, December 2021 e-ISSN: 2774-2121

https://journal-computing.org/index.php/journal-ita/index

\begin{tabular}{cc}
\hline 7 & $20,22,26,24,19$ \\
\hline 8 & $22,19,26,10,9$ \\
\hline 9 & $3,4,23,27,5$ \\
\hline 10 & $27,4,1,5,25$ \\
\hline 11 & $17,23,11,5,13$ \\
\hline 12 & $24,4,21,19,22$ \\
\hline 13 & $1,14,3,20,6$ \\
\hline 14 & $26,4,15,8,10$ \\
\hline 15 & $20,21,4,10,12$ \\
\hline 16 & $26,27,21,16,15$ \\
\hline 17 & $10,11,9,5,17$ \\
\hline 18 & $20,14,3,9,5$ \\
\hline 19 & $23,28,7,15,16$ \\
\hline 20 & $16,27,9,6,17$ \\
\hline
\end{tabular}

Tabel 3 merupakan hasil uji coba urutan soal baru yang dihasilkan oleh algoritma Fisher Yates Shuffle. Uji coba ini dilakukan pada menu kuis kategori kasroh dan dhomah. Kolom pertama berjudul PK atau percobaan ke- $x$, pada kolom kedua hasil urutan baru setelah aplikasi di jalankan.

Tabel 4. Uji Coba Fisher Yates Shuffle

\begin{tabular}{cc}
\hline PK & Hasil Urutan Baru \\
\hline 1 & $9,28,1,20,24$ \\
\hline 2 & $13,21,11,7,28$ \\
\hline 3 & $22,2,18,28,17$ \\
\hline 4 & $4,21,15,5,3$ \\
\hline 5 & $14,28,4,16,9$ \\
\hline 6 & $25,4,5,23,20$ \\
\hline 7 & $5,10,23,15,3$ \\
\hline 8 & $7,13,12,28,9$ \\
\hline 9 & $1,23,20,13,2$ \\
\hline 10 & $17,15,6,9,3$ \\
\hline 11 & $1,2,22,26,25$ \\
\hline 12 & $10,11,9,2,23$ \\
\hline 13 & $28,17,6,13,27$ \\
\hline 14 & $3,10,6,23,24$ \\
\hline 15 & $27,13,11,5,21$ \\
\hline
\end{tabular}




\section{Journal of Information Technology Ampera}

Vol. 2, No. 3, December 2021 e-ISSN: 2774-2121

https://journal-computing.org/index.php/journal-ita/index

\begin{tabular}{ll}
\hline 16 & $9,1,24,20,28$ \\
\hline 17 & $11,20,26,12,6$ \\
\hline 18 & $25,8,1,28,14$ \\
\hline 19 & $4,23,18,25,24$ \\
\hline 20 & $23,16,9,12,20$ \\
\hline 21 & $18,15,16,26,3$ \\
\hline 22 & $25,17,6,5,2$ \\
\hline 23 & $12,22,27,5,15$ \\
\hline 24 & $10,20,2,28,7$ \\
\hline 25 & $4,16,3,11,14$ \\
\hline 26 & $1,18,27,11,12$ \\
\hline 28 & $12,23,2,14,11$ \\
\hline 29 & $18,24,3,16,28$ \\
\hline 30 & $18,19,25,5,17$ \\
\hline
\end{tabular}

Tabel 4 merupakan hasil uji coba urutan soal baru yang dihasilkan oleh algoritma Fisher Yates Shuffle. Uji coba ini dilakukan pada menu kuis kategori fathah tain, kasroh tain dan dhomah tain. Kolom pertama berjudul PK atau percobaan ke- $x$, pada kolom kedua hasil urutan baru setelah aplikasi di jalankan. Uji coba ini dilakukan untuk membuktikan bahwa algoritma ini selalu menghasilkan hasil pengacakan yang baru setiap kali dijalankan. Hasil uji coba pada tabel 2, tabel 3, tabel 4, menunjukkan bahwa tidak ada satu pun urutan baru yang dihasilkan oleh algoritma Fisher Yates Shuffle sama dengan urutan yang lainnya.

\subsection{Aplikasi Belajar Huruf Hijaiyah}

a. Tampilan Menu Utama

Pada menu utama akan menampilkan menu - menu pilihan, terdiri dari belajar dan kuis yang memiliki fungsi masing - masing yaitu Belajar yang berfungsi untuk menampilkan beberapa kategori belajar dan Kuis yang berfungsi untuk menampilkan beberapa kategori kuis.

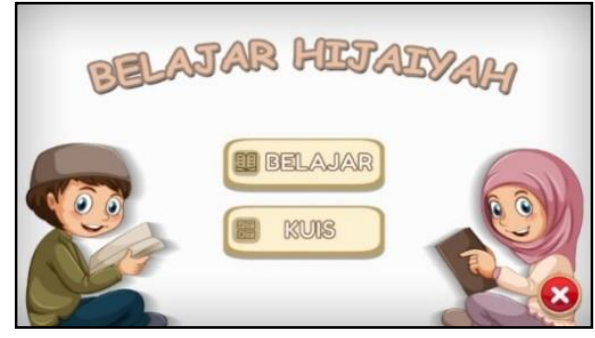

Gambar 5. Tampilan Menu Utama. 


\section{Journal of Information Technology Ampera}

Vol. 2, No. 3, December 2021 e-ISSN: 2774-2121

https://journal-computing.org/index.php/journal-ita/index

\section{b. Tampilan Menu Kategori Belajar}

Bagian ini yaitu tampilan yang akan muncul setelah memilih menu belajar. Pilihan ini akan menampilkan kategori belajar, terdapat 7 kategori belajar yaitu hijaiyah, fathah, kasroh, dhomah, fathah tain, kasroh tain, dan dhomah tain.

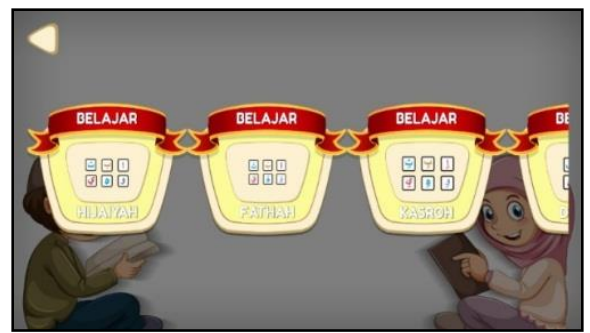

Gambar 6. Tampilan Kategori MenuBelajar.

c. Tampilan Menu Belajar

Setelah memilih kategori hijaiyah, maka akan tampil huruf - huruf hijaiyah seperti pada gambar Ketika usermenekan salah satu huruf, maka akan tampil pop up huruf dan suara dari huruf yang di tekan.

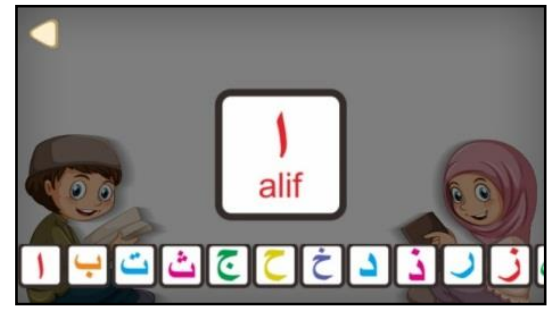

Gambar 7. Tampilan Menu Belajar.

d. Tampilan Kategori Kuis

Bagian ini yaitu tampilan yang akan muncul setelah memilih menu kuis. Pilihan ini akan menampilkan kategori belajar, terdapat 7 kategori belajar yaitu hijaiyah, fathah, kasroh, dhomah, fathah tain, kasroh tain, dan dhomah tain.

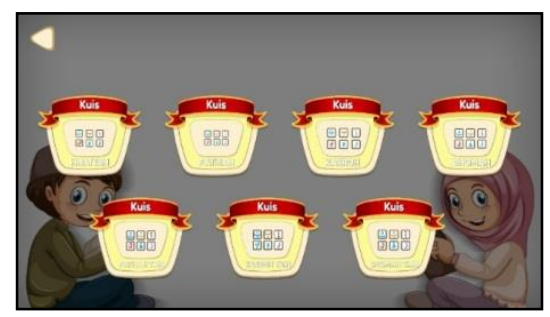

Gambar 8. Tampilan Kategori Menu Kuis. 


\section{Journal of Information Technology Ampera}

Vol. 2, No. 3, December 2021 e-ISSN: 2774-2121

https://journal-computing.org/index.php/journal-ita/index

e. Tampilan Menu Kuis

Setelah memilih kategori hijaiyah, maka akan tampil pilihan jawaban dan suara pertanyaan yang berkaitan dengan huruf hijaiyah. Ketika user menekan salah satu jawaban akan tampil pop up text benar atau salah tergantung jawaban user. Ketika user menekan tombol speaker maka suara dari pertanyaan akan di putar ulang.

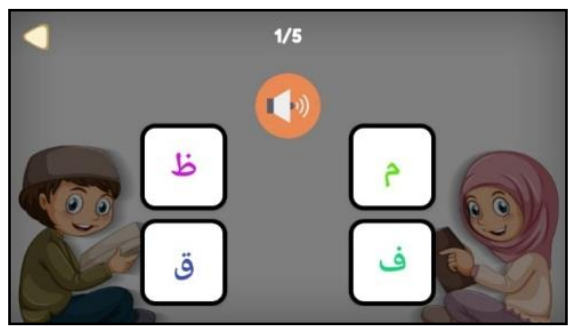

Gambar 9. Tampilan Kategori Menu Kuis.

f. Tampilan Halaman Skor

Setelah user menyelesaikan kuis maka akan muncul tampilan skor seperti pada gambar.

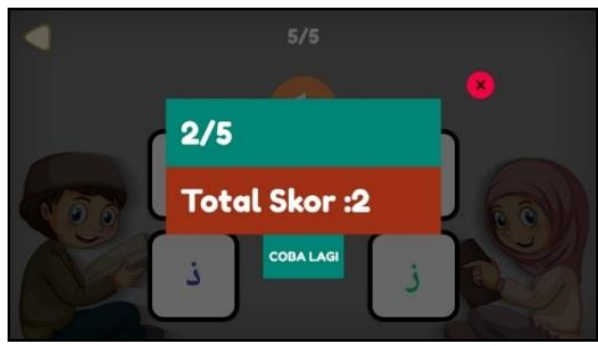

Gambar 10. Tampilan Skor Kuis.

\section{KESIMPULAN}

Berdasarkan hasil dari implementasi dan pengujian yang dilakukan terhadap aplikasi yang telah di buat pada penelitian ini, maka dapat ditarik kesimpulan di antaranya sebagai berikut:

1. Algoritma Fisher Yates Shuffle berhasil diterapkan pada Aplikasi Belajar Huruf Hijaiyah untuk mengacak soal kuis di dalam aplikasi, sehingga tidak terdapat soal yang sama di tampilkan secara berulang.

2. Penggunaan aplikasi Belajar Huruf Hijaiyah dapat dirasakan praktis dan akan memberikan bantuan kepada pengguna terutama pada anak - anak.

DAFTAR PUSTAKA

[1] Anggara prabawa, "Artikel Skripsi Universitas Nusantara PGRI Kediri," 


\section{Journal of Information Technology Ampera}

Vol. 2, No. 3, December 2021 e-ISSN: 2774-2121

https://journal-computing.org/index.php/journal-ita/index

2017.

[2] N. Safaat, "Pemrograman aplikasi mobile smartphone dan tablet pc berbasis android," Bandung Inform., 2012.

[3] I. Haditama, C. Slamet, and D. Fauzy, "Implementasi Algoritma FisherYates Dan Fuzzy Tsukamoto Dalam Game Kuis Tebak Nada Sunda Berbasis Android," J. Online Inform., vol. 1, no. 1, p. 51, 2016, doi: 10.15575/join.v1i1.11.

[4] R. A. Sukamto and M. Shalahuddin, Rekayasa Perangkat Lunak Terstruktur dan Berientasi Objek (Edisi Revisi). Bandung: Informatika Bandung, 2018.

[5] A. S. Rosa and M. Shalahuddin, "Modul Pembelajaran Rekayasa Perangkat Lunak (Terstruktur dan Berorientasi Objek)," Bandung Modul., 2011. 